\title{
Critical Turning Points During Lesson Study: Student Misconceptions Spark Teacher Learning
}

Excelsior: Leadership in

Teaching and Learning 2021, Vol. 13(2), 197-213

(C) The Author 2021

CC-BY 4.0 International Reprints and permissions: surface.syr.edu/excelsior https://doi.org/10.14305/in.19 440413.2021.13.3.02

Krystal A. Barber ${ }^{1}$

\begin{abstract}
During lesson study teachers collaborate to design, teach, observe, and reflect on a lesson with the overarching goals of improving instruction and increasing student learning. This article examines how a 6th grade mathematics lesson study project challenged teachers' ideas and assumptions about their students' understanding of fraction concepts. Significant misconceptions were revealed during the teaching of the lesson, prompting teacher learning and changes to instruction. The results highlight critical turning points during the process where evidence collected during lesson observations revealed student struggles and changed how teachers supported their students' thinking moving forward. This article also documents one teacher's journey as she recognizes the need for visual modeling and justification of math concepts to build deeper understanding. There are many different ways lesson study has been implemented in the United States, yet in many ways the effectiveness of lesson study remains uncertain. This paper focuses on key points during the lesson study process that can lead to the development of knowledge and practice.
\end{abstract}

\section{Keywords}

mathematics lesson study, teacher learning, student misconceptions

At a time when the United States is focused on student achievement, it is worthwhile to examine ways to support teachers in implementing new standards to increase student learning, improve instruction, and engage in productive collaboration. Teachers often face difficult working conditions, are asked to do more with less, and there is a growing perception of teaching as an undesirable career (Will, 2018). Lesson study can provide critical support for teachers, helping them to pursue professional learning

\footnotetext{
${ }^{1}$ SUNY Cortland

Corresponding Author: Krystal A. Barber, SUNY Cortland, Education 1248, P.O. Box 2000, Cortland, NY 13045 Email:krystal.barber@cortland.edu
} 
goals. Lesson study is centered on collaboration, examining student learning, and attaining student learning outcomes.

In New York State, more than 130 educators and parents revised the National Common Core Standards, resulting in the recently adopted Next Generation Learning Standards for Mathematics. These newly revised standards require students to be mathematically proficient, meaning students comprehend math concepts, carry out procedures, represent and solve math problems, explain and justify their thinking, and see mathematics as a worthwhile endeavor (Kilpatrick et al., 2001). When students have conceptual understanding in mathematics, they have a deep understanding of math concepts and relationships and can apply these to different contexts. Students who display procedural fluency can carry out mathematical procedures (like the algorithms for addition and subtraction most adults can recall learning in school) and can use these accurately, efficiently, and flexibly. Mathematical proficiencies such as these are interwoven and should not be developed in isolation. It is a challenging task for teachers to create strong links between conceptual understanding and procedural fluency. Creating these connections requires teachers to build a strong foundational knowledge of math concepts, to support meaningful representations, and to help students understand how and why different procedures make sense (Ball et al., 2008).

Enhancing content knowledge and improving teaching practice are common goals of teacher professional development. Research has shown that high-quality, effective professional development takes place within the context of the classroom and is focused on student learning (Borko et al., 2010). Lesson study addresses both of these characteristics and can lead to positive learning opportunities for teachers.

\section{Review of Literature}

\section{Lesson Study Process}

Lesson study can be outlined as follows: identify a broad goal for student development, create a specific goal for student learning, plan a lesson that addresses these goals, teach and observe the lesson, collect data on student learning, reflect on the lesson and revise, and share results (Murata, 2011). Teachers work as a team during lesson study to identify goals and plan the lesson. One teacher on the team teaches and other team members observe, collecting evidence on students' strategies and ideas. The team reflects on the data collected, sometimes revising the lesson and teaching again, then sharing results.

In Japan, lesson study is not just a single, isolated activity; rather it is the continuous process of professional development and reform that teachers take part in throughout their careers (Fernandez, 2002). Makoto Yoshida developed the phrase "lesson study" from the Japanese word jugyokenkyu where jugyo means lesson and kenkyu means study or research; however, it was Catherine Lewis (1998) who called these "research lessons." Lewis uses this title to highlight the fact that teachers systematically examine the planning and implementation of lessons.

Lesson study works to improve teaching in the context of the classroom so there is no gap between research and practice. Collaboration promotes further reflection of teaching practice. "Teachers are able to develop a shared language for describing and analyzing classroom teaching, and to teach each other about teaching" (Stigler \& Hiebert, 1999, p. 123). Lesson study eliminates the isolation of teaching, promoting not only shared language, but also a shared understanding of effective instruction. 
Participating in lesson study enables teachers to see themselves as professionals and as researchers, developing knowledge and practice, and sharing that learning with others. Lesson study is "a research process, intended to produce learning on the part of teachers that can then be applied to improve their future instruction" (Stigler \& Hiebert, 2016, p. 582).

\section{Teacher Learning Through Lesson Study}

Lesson study is way for teachers to learn and apply new ideas to strengthen instruction. Professional learning communities where teachers work together while gaining a deeper understanding of their students as learners are most effective for improving instruction (Borko et al., 2010). Fernandez and Yoshida (2004) highlight the numerous opportunities lesson study provides for teachers to learn and improve their practice, including discussing mathematical content and pedagogy, anticipating student solutions, establishing goals for student learning and development, and influencing teacher attitudes and beliefs about practice. Features of lesson study that contribute to instructional improvement are creating long-term goals for student learning, studying curricula and standards, planning and teaching the research lesson, collecting evidence on student learning, and presenting and sharing results. These features create three different learning pathways: development of teachers' knowledge, increased motivation and collaboration within the professional community, and examination of tools and resources that support learning (Lewis et al., 2006). A unique element of lesson study is that teachers develop "the eyes to see students" (Lewis, 2002). Focused observation of students enables teachers to take time away from the activities of teaching and instead focus on learning. A critical lens on students' ideas, strategies, and behaviors provides concrete evidence that can inform instruction and impact student achievement. Dudley (2012) found that schools where lesson study is employed showed higher levels of student achievement than comparable schools.

Researchers have found changes to teachers' content knowledge and pedagogical beliefs are affected by the collaborative nature of lesson study and its tendency to make thinking and knowledge visible (Fernandez \& Yoshida, 2004; Kamina \& Tinto, 2011). Lesson study can increase teachers' attention to students' mathematical thinking, helping teachers document how pedagogical decisions affect student learning (Alston et al. 2011). Alston et al. (2011) found that teachers benefited from lesson study in three ways: they were able to recognize and follow student thinking, they were able to document and describe student strategies and solutions, and they realized how the implementation of instruction affected student learning.

Pang (2016) examined how teachers in Korea made changes to instruction as a result of a lesson study cycle focused on orchestrating productive discussions. Pang found that instruction became more dynamic, with students exploring multiple solutions and engaging in more challenging tasks. Fernandez (2009) found that lesson study gave teachers rich opportunities to learn about mathematics for teaching to successfully implement "reform-minded teaching." Reform-minded teaching focuses on developing deep understanding of mathematical concepts, making connections between concepts, presenting students with challenging tasks, and engaging students in rich mathematical discussion. Fernandez also found that while limited content knowledge can sometimes hold teachers back from learning, the cyclic nature of lesson study aids teachers in developing this knowledge. Learning communities such as lesson study can support "high-functioning" involvement, meaning teachers seek to understand student thinking more deeply, using specific evidence as a basis for their understanding. "In lesson study, teachers' partial understanding often becomes visible, and in safe, collaborative settings 
it is possible for teachers to discuss and make sense of the challenges together, seek necessary information, and develop new and shared knowledge" (Murata et al, 2012, p. 640). Lewis et al. (2013) found strong common themes when conducting lesson study with three different groups of teachers, including eliciting and analyzing student thinking, encouraging students to problem solve, and utilizing multiple representations. The researchers attributed the emergence of these themes to both the process of lesson study itself and to the shared values of the participants. Lesson study as professional development sets the stage for teacher learning, respecting the cultural nature of teaching as teachers collaborate to develop professional knowledge (Murata, 2011; Stiger \& Hiebert, 1999).

Lesson study can create a pathway between national goals and classroom practice (Lewis \& Tsuchida, 1999; Takahashi \& McDougal, 2016). "As they plan and conduct research lessons, teachers not only construct a concrete understanding of abstract national goals such as 'problem-solving capacity' and 'autonomous learning', they help each other develop the specific techniques and materials needed to bring these ideas to life in classroom practice" (Lewis \& Tsuchida, 1999, p. 329). Teachers have the opportunities to take broad goals such as conceptual understanding, discuss what these goals mean, and explore and define them in the context of their everyday classrooms. Teachers exchange knowledge and experiences, read research articles, examine curricula, and collaborate to plan the lesson. Then teachers can decide if students learning outcomes were attained, enabling them to make changes to instruction.

The research presented here demonstrates the power of lesson study to develop knowledge around mathematics and teaching, to improve instructional practice, and to help teachers attend to student thinking. While research supports teacher learning during lesson study, how this learning occurs remains uncertain. For example, what are the conditions, discussions, and key points in the process that support teacher learning and lead to instructional change? This research contributes an analysis of critical points in the lesson study process and how these created pathways for teacher learning and changes to teacher practice.

\section{Research Design}

The study aims to answer the following research questions: What are critical points in the lesson study process that lead to teacher learning? How do these critical points create a pathway between teacher learning and improvements to instruction? To identify these critical points a qualitative, case study research design was employed. During the lesson study cycle, observations of classroom lessons, semistructured interviews with teachers, and participant observation provided evidence of participants' knowledge, experiences, and instructional decisions and actions. This article focuses on the experiences, teaching, and discussions of a 6 th grade math lesson study group. University teacher educators provided support around the process of lesson study and the planning of the lesson. These specialists provided mathematics content support and contributed to discussions by asking questions and facilitating teacher talk.

\section{Data Collection and Analysis}

The following data were collected for the study: audio-recorded interviews with each teacher before and after lesson study, field notes from classroom observations, video-recordings of lesson study meetings, lesson-related materials (lesson plans and student work), and teacher notes (collected during 
the teaching of the lesson). Interviews and observations took place with each teacher individually before and after the lesson study cycle. The semi-structured interviews followed a protocol aimed at providing context for teachers' mathematics instruction, including pedagogical strategies and instructional decisions. To supplement data from teacher interviews, I observed one classroom lesson taught by each teacher before lesson study and one classroom lesson taught after lesson study. The interviews and observations before lesson study provided baseline data for the study. The interviews and observations after lesson study captured changes to teachers' ideas and instruction, helping to determine how lesson study influenced teacher learning and practice. Video analysis of lesson study meetings provided evidence of key discussions that took place during planning and debriefing sessions. Lesson-related materials, teacher notes, field notes, and student work also supported the depth of analysis and provided further evidence of teacher learning and changes to practice.

Case study analysis was used to examine how the characteristics, processes, and points in the lesson study process led to teacher learning and changes to practice. Transcriptions of audio and video recordings, field notes, and teacher notes were analyzed holistically to create a coding scheme. These codes were organized and conceptualized into categories, providing overarching meaningful themes. Analytical memos were written to more closely explore certain topics, such as the teachers' knowledge of mathematical concepts and procedural skills, pedagogical strategies for teaching mathematics, planning of math tasks and questioning, and insights that occurred after collecting evidence on student learning.

The Clarke and Hollingsworth (2002) Interconnected Model of Professional Growth (ICMPG) was used as a theoretical framework. This model recognizes that teacher learning is revisited and changed iteratively among four domains: knowledge, belief, and attitude; professional investigation and instruction; outcomes of teacher actions; and sources of information that prompt learning. Because this model is analogous, in many ways, to the process of lesson study, it enabled me to examine how different points in the lesson study process were critical for prompting teacher learning and changes to instruction.

To answer the first research question, the lesson study group served as a unit of analysis. Discussions and collaborations of the group as a whole were analyzed at each step in the process (identifying goals, planning the lesson, teaching the lesson, collecting data and reflecting, revising and re-teaching, reflecting again). Analysis of group discussions and instructional decisions as the teachers went through this lesson study cycle allowed me to identify critical points in the process. To answer the second research question, the $6^{\text {th }}$ grade teacher, Catherine, was analyzed as a single case study. Using Catherine as a single unit of analysis allowed me to focus on her individual learning pathway, while considering the critical points identified. This two-part analysis captured key exchanges and turning points in this lesson study process and revealed discussion points and evidence of student thinking that prompted teacher learning and led to changes to instruction.

\section{The Lesson Study Team}

This $6^{\text {th }}$ grade lesson study team included Catherine, Nancy, and Jeff, teachers at a K-6 public elementary school in the central region of New York. The school is located in a suburban school district. At the time of the study, the students in this school were predominately White (approximately 75\%) with the remaining $25 \%$ consisting of students who were Black/African American, Hispanic/Latinx, Asian, Hawaiian, or multiracial. According to the school report card, $50 \%$ of the students were classified 
as economically disadvantaged and approximately $20 \%$ of population consisted of students with disabilities. The team also had support from several individuals who served as outside experts: Lynn, a university faculty member and lesson study researcher, Maria, a mathematics education graduate student, and Renee and Karen, mathematics education university faculty. Outside experts can strengthen the lesson study process significantly. The role of each of these experts was "to raise questions, add new perspectives, and be a co-researcher" (Lewis \& Hurd, 2002, p. 33). The outside specialists supported teachers by providing resources, answering content- and process-related questions, and by taking part in discussions. These specialists did not act as an authority on teaching, but instead were there to enrich the lesson study process.

\section{Findings}

The 6th grade lesson study team purposefully selected tasks that moved beyond a focus on procedural understanding and encouraged students to represent their thinking with explanations and modeling. The goal of the lesson was to deepen students' understanding of division of a whole number by a fraction and division of a fraction by a fraction with visual models and justification, as opposed to having students rely on a memorized procedure. One of the biggest misconceptions with division of fractions is not understanding what the common algorithm "invert and multiply" means (Van de Walle et al., 2018). To address this, the lesson study team required students to model and explain their solutions. Key discussions took place during the planning meetings, before the first implementation of the lesson. These exchanges provide background for turning points that took place later, after the first teaching of the lesson.

\section{Discussion: Attaching Meaning to Procedures}

During the first planning meeting, teachers openly discussed their own struggles with understanding certain mathematical concepts, even as adults, and the challenge of attaching meaning to mathematical procedures.

Lynn: Maybe it would be helpful to talk about some ways in which you multiply and divide fractions?

Catherine: Well I think baking, construction ...

Nancy: I'm so bad at it, when I have to [convert fractions] I go to the computer and I find a conversion. That's how bad I am.

Catherine: Well, I think that's what kids face too. If you ask most adults will remember multiplying by the reciprocal to divide [fractions] but they don't really understand what that means. And I think that's the same challenge that kids have.

Jeff: I think you can only go so far when you only follow the rules.

Catherine: It's true.

Nancy: Because you don't really get the concept. You just get the mechanics of it. And we're trying to get them to learn the concept.

Lynn: How is multiplying and dividing fractions building off of what they already know about multiplication and division of whole numbers? And how does it require them to leverage what they know about fractions? Maybe it's helpful to talk a little about what kinds of ideas do we think 
students have about multiplication and division of whole numbers and separately talk about their ideas about fractions and then try to see what we think when we bring those together.

(6th grade team, planning meeting 1 )

In the excerpt above, Lynn is supporting the teachers during the planning process by prompting them to consider utilizing students' prior knowledge.

\section{Figure 1}

Set of tasks for the lesson

Launch/Introduction Problems:

$12 \div 4=3$. What does this equation mean? How would you represent (model) this?

$12 \div 1 / 2=\ldots$.-. What does this equation mean? How would you represent (model) this?

Explore/Problem Set:

Solve the problems below. You will need to model and explain your solutions.

1. $\frac{1}{2} \div \frac{1}{4}=$

2. The baker has $\frac{7}{8}$ of a pound of sugar left. He needs $\frac{2}{8}$ of a pound of sugar for each batch of cookies he makes. How many batches of cookies can he make with $\frac{7}{8}$ of a pound of sugar?

3. $X Y Z$ construction company has a board left over from the playground project measuring $\frac{3}{5}$ of a foot. Pops wants $\frac{1}{4}$ foot pieces to use as bookends on her new book shelf. How many bookends can she make?

During the second planning meeting, Renee helped the team continue to refine their ideas around building understanding of procedures. She prompted the teachers to delve deeper into understanding the algorithm for dividing a fraction by a fraction and guided them in using these ideas to plan their lesson.

Renee: Something common we see at the university is that if students are struggling, they don't understand what it means to divide fractions. So, one of the big questions we ask them is when you are dividing fractions why do you multiply by the inverse?

Nancy: And the answer is?

Renee: If you have $6 \div \frac{1}{2}$ what are you really asking?

Catherine: How many halves are in 6 . So, in each unit it's the reciprocal. Maybe we could even start with whole numbers.

Renee: Like $6 \div 3$, and have the students think about what that problem is asking.

Catherine: So, if we establish a pattern and then pull back our support of that pattern.

Renee: Even if you ask $3 \div 6$. It's asking how many 6 's are in 3 . Well there's only a half. So, you end up with a fraction.

Catherine: So, start with a whole number, model, and then slowly go into what does 12 divided by 
$1 / 2$ mean? Maybe that is the next step. Then maybe the true challenge would be [dividing a] fraction by fraction.

Nancy: Give me an example.

Catherine: We probably want to start with something with like denominators.

Maria: What if we did $\frac{1}{2} \div \frac{1}{4}$ ? It would be really easy to model that to see how many fourths are in one half.

Nancy: And throughout keep asking them, what does that mean? Because our rationale is that students might learn the procedure, but can't really explain it.

Catherine: Right. Well they go straight to the algorithm but can't really explain what that algorithm means. They'll just say, "Same, change, flip." And we'll say, "Well how do you divide fractions?

What does it mean to divide fractions?" (6th grade team, planning meeting 2 )

Before this discussion, the teachers expressed their desire to have students understand the meaning behind the procedure for dividing fractions, however, they were uncertain of how to accomplish this goal. These conversations helped teachers develop their tasks for the lesson (see Figure 1). This also solidified the choice to have students model solutions and explain their thinking.

\section{Discussion: VisualModels}

One visual model discussed by the teachers was a tape diagram (also called "strip diagram" or "bar diagram"). This is a semi-concrete visual where a rectangular diagram is used to visualize mathematical relationships and to help students show their thinking (See Figure 2).

\section{Figure 2}

Tape Diagram Modeling $\frac{1}{2} \div \frac{1}{4}=2$

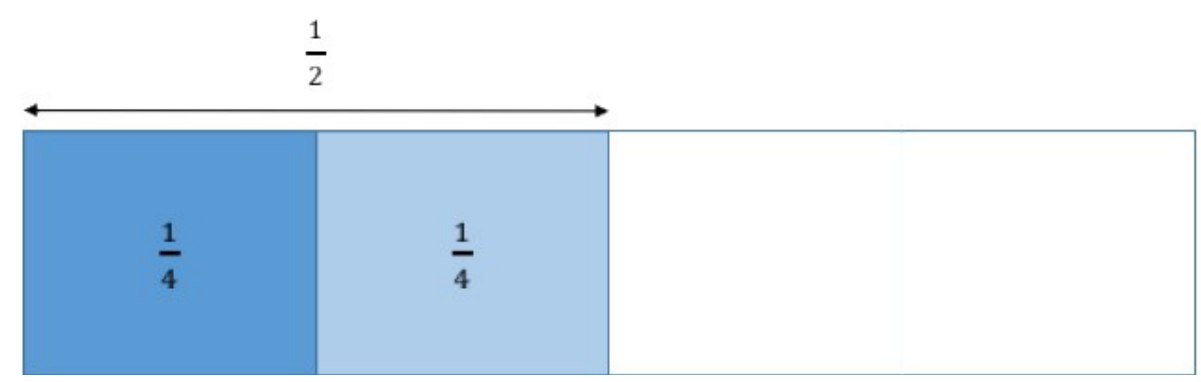

Catherine: A model is a good way for students to persist when they struggle and that is a good way to support eventually doing a standard algorithm for multiplying and dividing fractions. It might be a good idea to start picture or with a model of some sort.

Lynn: What models have you found most useful to help students think about multiplication?

Catherine: Tape diagram or a bar model. Like using tape shaped pieces, so longer rectangles. Maria: What about pattern blocks?

Catherine: Pattern blocks? Probably earlier in their career. I'm not sure how it's approached in the intermediate grades.

Catherine: Do you know if they have any fraction bars because those are shaped like tape diagrams? I had so many resources, I should have taken some of them with me. But that would be 
easy to copy and make.

Lynn: Why do you find tape diagrams so important?

Catherine: It's a consistent shape, first and foremost.

Nancy: It's always a rectangle.

Catherine: It's consistent yes. Everybody can draw a rectangle so they are not messing around with different shapes like pattern blocks or...that's one piece out of the equation. (6th grade team, planning meeting 1 )

Although tape diagrams can be a very useful model for students, Catherine seemed set on this being the only representation students should use for exploring fraction computation. Relying on only one representation can restrict students' thinking and lead to a rote use of this tool. Problems that involve dividing whole numbers by fractions can also be difficult to represent with a rectangular diagram. Figure 3 shows an example of the equation $12 \div 1 / 2=24$ using pattern block manipulatives. Students could also represent this problem by drawing a picture, for example by drawing 12 circles or rectangles.

\section{Figure 3}

Modeling $12 \div 1 / 2=24$ Using Pattern Block Manipulatives

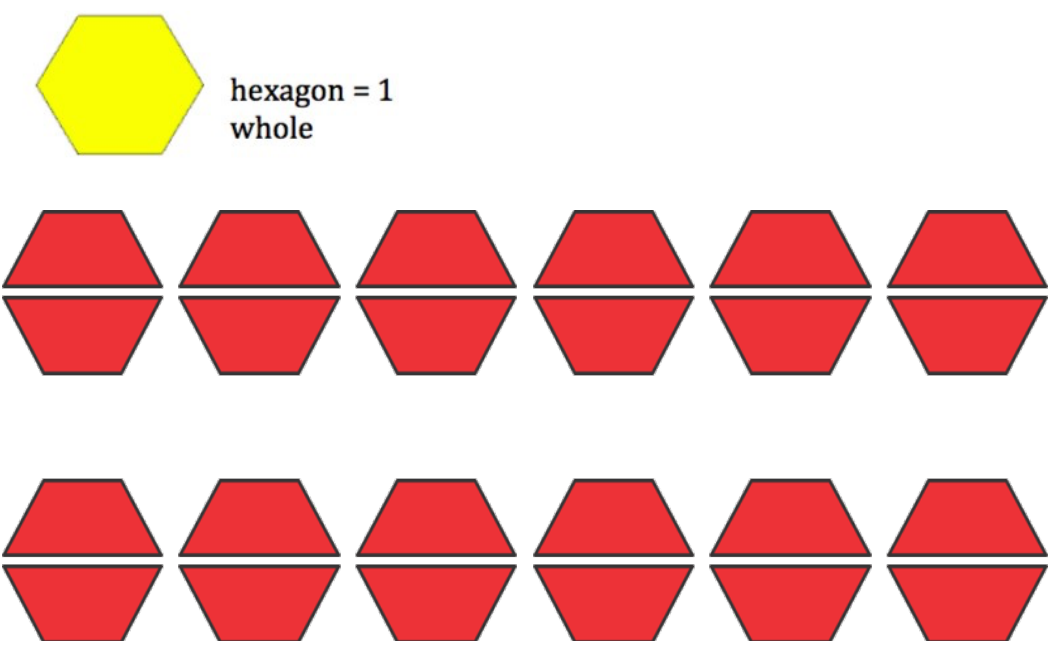

\section{Discussion: Modeling and Justifying not Rigorous Enough?}

The following discussion took place during the final planning meeting and demonstrates the teachers' concerns that the lesson would require minimal effort on the part of the students and students would finish too quickly. The teachers were concerned the lesson lacked rigor, despite previous discussions that established having students model solutions and justify their ideas poses a challenge.

Jeff: So that's our entire lesson, those three problems?

Catherine: We can add another one and if we don't get to it we don't get to it. Maybe we can have two more that are context problems, that are word problems. ...

Jeff: There's no way we are getting an hour out of this lesson. 
Maria: I disagree. I think we will definitely get that because it's going to be a lot of rich discussion about what this really means. They are going to have to model it and they are going to have to present their strategies. Catherine: And explain their thinking.

[Team members agree with Jeff, but decide it will be fine if the lesson runs short.]

(6th grade team, planning meeting 3 )

Experiences involving low rigor often focus on the quantity of tasks rather the quality. The teachers did not consider the time students needed to create models, which requires building a mental image of different quantities, and to engage in mathematical discussion. The teachers believed students would quickly and easily solve the problems planned for the lesson. It is important to note that this group of $6^{\text {th }}$ grade students were seen as high-level math learners, with the majority of the class performing above grade level on benchmarking and state tests. Catherine suspected that these students had procedural fluency, meaning they had memorized and could execute procedures very well. However, she also suspected they would have trouble explaining their thinking and understanding how and why these procedures worked. While a problem like $12 \div 1 / 2$ can be simple if a student knows an algorithm (for example, invert the divisor and multiply by the reciprocal), students were asked to model this problem with a drawing and explain their reasoning.

These discussions provide important context for examining what happened later during the teaching of the lesson and during the debrief after the lesson. These exchanges were important developments in the planning process and led to turning points which took place after the first teaching of the lesson.

\section{Turning Point: Misconceptions Revealed}

Two problems were chosen to introduce the lesson, $12 \div 4$ and $12 \div 1 / 2$. These problems were purposefully chosen to connect to students' prior knowledge. The lesson began with $12 \div 4$ to discuss what it means to divide two numbers and what the solution represents. Teachers wanted students to explain that this can be thought of as "How many fours are in 12 ?" The next problem, $12 \div 1 / 2$, was chosen to connect to the idea of "How many halves are in 12 ?" This type of problem is explored in $5^{\text {th }}$ grade as part of New York State standards. In sixth grade, students begin dividing a fraction by a fraction, which was meant to be the focus of the day's lesson. The team expected that students would find these introductory problems simple and straightforward. Yet, not a single student was able to accurately model and solve the problem $12 \div 1 / 2$. The team expressed their profound surprise regarding student struggles and misconceptions.

Jeff: They didn't even know how to do the algorithm. They all got six, every single person got six [as a solution to the problem 12 divided by $1 / 2$ ].

Karen: I like how they manipulated the algorithm in order to get six.

Jeff: I don't think they got anything out of it.

Jeff: Ella wrote it correctly and then Natalie convinced her to change it back to six. A lot of them converted to decimals.

Catherine: They were so uncomfortable with fractions that they converted to decimals. But if you talked to Aaron about it he thinks he can teach my class. That's the problem, their perceptions of their math understanding ... it's not deep. It's so literal. I could fast forward ten years and these kids 
who could be successful in math are not going to go into math and science fields because they are not going to have that deep understanding. And that's what's scary.

Nancy: I was shocked to see with that first one $[12 \div 1 / 2]$ they came up with six and they did anything that they could to make the answer six.

Jeff: I have a feeling it goes deeper than that and they don't even understand what a fraction is. Karen: Using pattern blocks would be helpful because it would give the students a concrete visual to work from.

Catherine: They should have been using manipulatives for years before they ever get to the algorithms because by this point you expect them to understand the concept but it's clear they do not have the concept of fractions. We are expecting them in sixth grade to divide fractions with like denominators and unlike denominators.

Karen: Student proficiencies begin to fall off from $5^{\text {th }}$ to $8^{\text {th }}$ grade because they are supposed to use these concepts and apply them to things like decimals, fractions, and proportions, but if they never fully understood those to start with, they can't master more difficult concepts. So that's why you are seeing what you seeing because it's possible they never really understood division. And then they get to this and don't even know where to start. ( $6^{\text {th }}$ grade team, lesson debrief)

These results were unexpected and eye-opening for the teachers. The lesson study team expected students might have trouble modeling or explaining their thinking, however, they were confident that students would be able to solve the problems correctly because of their strong knowledge of procedures. The lesson revealed that students were unable to model or solve accurately, and that students struggled to discuss key ideas, even those related to dividing whole numbers. The evidence collected during the lesson revealed misunderstandings of division and fractions concepts, and the discussions that followed changed how teachers supported their students' thinking moving forward.

\section{Turning Point: Critical Need for Concrete Modeling}

Before the teaching of the lesson, the team was reluctant to use concrete manipulatives, specifically pattern blocks. Catherine believed these were better suited for the early grades and was insistent on using tape diagrams. However, when the teachers recognized student misunderstandings, they became willing to consider different representations to help students make sense of the concepts. During the debrief, the team was concerned about how they could support students to develop accurate models. They decided to include the use of concrete manipulatives and to include more scaffolding and questioning strategies to support students' explanations. For example, they would introduce the hexagon pattern block first and ask "How many halves are in one? How many halves are in two? How many halves are in 12?" During the second teaching of the lesson, the use of concrete manipulatives proved helpful in pushing students toward correct representations and the questioning strategies used by the teacher helped students make sense of these ideas.

The group ended the lesson study cycle with compelling evidence of what their students understood, and still did not understand, about fraction models and division of fractions. The lesson study team realized the importance of using different representations for modeling concepts and supporting conceptual modeling with questioning and discussion.

These findings identify key discussions among the group during the planning process and after the implementation of the lesson. These exchanges and turning points represent important developments 
during the cycle. These demonstrated how teachers saw student misconceptions firsthand, revealing the need for students to create visual models and explain their thinking. Insights into students' ideas and misconceptions brought about shifts to instruction after the lesson study cycle was complete.

\section{$6^{\text {th }}$ Grade Teacher Catherine}

Catherine was a new teacher at this school and new to this school district. She had six years of teaching experience at nearby school district. This was Catherine's first lesson study cycle. Prior to lesson study, Catherine was incorporating some visual models to help her students make sense of mathematical ideas. As discussed previously, one visual model she used often was a tape diagram, which can be useful for creating a picture to show mathematical thinking. Throughout the lesson study cycle, Catherine expressed her belief in the importance of incorporating visual models to help students make sense of mathematical ideas. She also believed it was important for students to explain their thinking.

Catherine's primary concern was that her students could execute procedures easily, but lacked a deep conceptual understanding.

A pathway to improving practice. Lesson study gave Catherine an opportunity to become a researcher within the context of her own classroom and to collaborate with her new colleagues. Lesson study impacted her beliefs about her students' abilities, ideas, and actions, and impacted her knowledge of teaching strategies needed to strengthen students' mathematical understanding. Exploring direct evidence of students' thinking resulted in Catherine making shifts to her practice after lesson study was complete. After lesson study, Catherine began incorporating multiple representations. Catherine had students explore mathematical concepts using a variety of models and representations, including diagrams, pictures, and concrete manipulatives. Catherine also increased her requirement that students justify their ideas. During a postlesson study observation, Catherine incorporated concrete tools, provided fewer answers, and pushed students to explain their thinking.

Lesson study, for me, was a chance to sit back, pick one thing to do well, and look deeply at it. That really enriches everything. Since then, I've been trying to build in more use of manipulatives, more use of problem solving and thinking, and not giving answers as quickly, or confirming answers as quickly. So even when the kids were working on their homework, I had three different kids working on a tougher problem at the end of their set say, "Is this right?" and I said, "Well, what makes you think it's right?" I have them explain a little bit more and I didn't tell them whether it was right or wrong I just said, "Well, we'll talk about it tomorrow." I think that's good. That's a shift that's hard to make as a teacher. It's hard to let go of control. But I know that being an "answer giver" is not helping them learn math. (Catherine, post-interview)

During our follow-up lesson observation and interview, Catherine demonstrated her focus on supporting students by using visual models and by using questioning to ensure students were building a deep understanding. After lesson study, Catherine recognized where her students fell short and was determined to address these shortcomings, regardless of how students performed on progress monitoring or standardized assessments.

We give regular progress monitoring measures. You actually saw one at the beginning of class - to 
see how good these kids are at performing what are considered fluency tasks at a 6th grade level. They are proficient, majority of them. But you look at a concept like fractions that starts in early primary, and when you ask them questions that are really below grade level and realize that they don't understand it, it's alarming. So now we've created this body of thinkers that really have no depth to their understanding. They just ... they can perform tasks and sometimes they recall how to perform the tasks and sometimes they don't, but when they don't it's usually detrimental and what's more detrimental is they don't understand what they're doing. (Catherine, post-interview)

What was made apparent throughout this lesson study cycle was Catherine's concern that these students had procedural fluency, but that students could not explain key mathematical concepts. After lesson study, Catherine felt more support from her colleagues and even from her principal. She was determined to support student learning and realized she might have to look critically at the resources and tools she was using to do this.

We are encouraged by our district to use the resources they give us ... so, I think teachers are under the impression ... it's tough ... you want to use the resources, but sometimes you have to supplement with other things. Luckily, Tom [the principal] is so supportive. He really trusts me and has said, "I trust that you know your students, that you are basing your decisions on data, and that you can reinforce in small groups; whatever decision you make, I'll support." I think if I stored the workbooks in my cupboard he'd be a little disappointed but I mean .... It's unfortunate that we spend that much money. It would be nice to see some of the money go toward lesson study or something to really enrich learning.

$\cdots$

In the long run looking forward, if I see what their shortcomings are I need to address that. That's really my primary job. I need to help them learn. So, if the workbook does it great, if it doesn't then I need to find something that does. (Catherine, post-interview)

Catherine's conclusions here are quite powerful. The exchanges and turning points identified demonstrate Catherine's recognition of student misconceptions and the need to make changes to her practice to better support students' understanding of these concepts. Catherine realized she would need to focus on modeling, to require justification, to examine where students needed more support, and to address that head on. Discussions of procedural knowledge, visual modeling, and justification of student thinking contrasted with seeing evidence of student misunderstandings during the lesson. This created a pathway for learning and resulted in Catherine making significant shifts to her practice to support a deeper understanding of mathematical concepts.

\section{Discussion}

Lesson study provides significant opportunities for teachers to set and attain goals for student learning and for instruction. Teachers work together to deepen their understanding of student ideas and examine their own practice in a context that is meaningful and relevant to them. Yet, how teachers learn during lesson study still requires more attention. These results highlight instances of teacher learning that came about during critical points in the lesson study process. These turning points provided a pathway for new learning and led to changes to instruction. Eliminating outside, knowledgeable experts is one way 
that lesson study is sometimes modified in the United States leading to challenges (Yoshida, 2012). The outside experts in this study proved to be a critical factor for supporting lesson plan development and contributing to key group discussions.

The discussions explored in the findings demonstrate teachers' desire to help students attach meaning to the procedures they already know and use, teachers' notions of modeling fraction computation, and teachers' concerns over the few number of problems planned for the lesson. These discussions provide context for a pivotal point in the data - when teachers' assumptions were challenged by their observations of student struggles during the lesson. This evidence revealed deep misunderstandings of both fraction and division concepts. This evidence prompted teachers to recognize the need for concrete modeling combined with the support of rich mathematical discussion. Students acquire proficiency by following a progression of learning in mathematics. Direct modeling and concrete representations pave the way for the use of more advanced and efficient procedures (Kilpatrick et al., 2001). Physical manipulatives can also offer a means for students to test out their ideas and can help build understanding, however, manipulatives must be used in a way that creates meaning. For example, teachers can combine manipulative use with purposeful mathematical discussion during the course of the lesson to promote understanding (Furner \& Worrell, 2017).

The turning points identified support a common theme - evidence collected during the lesson challenged teachers' ideas and assumptions about student learning. Without the evidence collected, and subsequent discussions, teachers may not have been prompted to adjust their limited use of mathematical representations and to increase their requirement that students justify their thinking. When the teachers witnessed misunderstandings, they became willing to incorporate representations other than tape diagrams to help students make sense of the concepts. The results of the lesson also prompted more eliciting and justifying of student thinking. Having a student explain his or her strategy is an important way they can participate in mathematical discussion in the classroom. However, justification takes explanation a step further by asking students to provide evidence and reasoning for their ideas and solutions. "Students need to be able to justify and explain ideas in order to make their reasoning clear, hone their reasoning skills, and improve their conceptual understanding" (Kilpatrick et al., 2001, p. 130).

Catherine's experiences demonstrate a pathway of learning. Student misconceptions brought about shifts to her instruction after the lesson study cycle was complete. Catherine began to incorporate the use of various representations, including concrete and semi-concrete models. She also increased her requirement for students to justify their thinking. It was the student difficulties representing and articulating conceptual ideas during the lesson that convinced Catherine, as well as the other teachers in the group, that the students needed to be pushed more to show their understanding. Catherine realized she was being an "answer-giver" all too often for her students.

This study identifies key points in the lesson study process, pinpointing where teachers revised their ideas about student learning and made improvements to practice. This study aligns with the tenets of effective lesson study, including proper support, reflection, knowledgeable outsiders, and maintaining a focus on student thinking, which also supported teacher learning. Perhaps the most important feature of any professional learning community is continued participation to maintain growth. Lesson study has the potential to support teachers to use what they know and what they learn to drive instruction and to participate in an ongoing, long-term investigation of effective practices. 


\section{Implications}

Lesson study has the potential to impact both teacher development and teacher education. Effective partnerships between university teacher education programs and P-12 school districts are essential for the continued success and development of both schools and colleges. National organizations, such as The Council for Accreditation of Educator Preparation, have focused on creating strong, reciprocal partnerships that enhance both instruction and student learning (CAEP, 2015). In that respect, lesson study could be used as an essential tool for building coalitions that explore best practices, examine student learning, and strengthen the connection between teacher educators and teachers. In Japan, lesson study is a powerful and effective form of professional development that has helped teachers successfully implement changes to the national curriculum. "Japanese mathematics instruction has transformed from teacher-directed instruction to child-centered instruction during the past fifteen years" and this change has been attributed to the country's primary method of professional development-lesson study (Takahashi \& Yoshida, 2004, p. 436). Lesson study could do the same in the United States to implement New York State's Next Generation Mathematics Learning Standards. How lesson study is different from other professional learning communities is that it often challenges initial ideas and assumptions, prompting the development of knowledge and enabling teachers to make significant shifts to instructional practice (Brodie, 2014).

Lesson study has taken many different forms across the US, at times serving different purposes. To meet their needs, schools or groups of teachers might select or adapt components of lesson study, or they might leave out important steps (like teaching and observing a research lesson). While it may not be possible to implement lesson study in the same way that it is implemented in Japan, adapting lesson study in the US can still result in success so long as adaptations respect essential elements and goals (Stigler \& Hiebert, 2016) as was demonstrated in this study.

For lesson study to make a lasting impact, we still need to understand more about this process, how the process unfolds when the settings and goals vary, and what are significant points in the lesson study process that can lead to development of teaching and learning. One thing is certain, direct evidence of student thinking within the context of the classroom is an essential component that can impact teacher learning and spark meaningful instructional change.

\section{Declaration of Conflicting Interests}

The author declared no potential conflicts of interest with respect to the research, authorship, and/or publication of this article.

\section{Funding}

The authors received no financial support for this research.

\section{References}

Alston, A., Pedrick, L., Morris, K., \& Basu, R. (2011). Lesson study as a tool for developing teachers' close attention to students' mathematical thinking. In L. Hard, A. Alston, and A. Murata (Eds.), Lesson study research and practice in mathematics education (pp. 135-151). Springer. https://doi.org/10.1007/978-90-481-9941-9_11 
Ball, D., Thames, M., \& Phelps, G. (2008). Content knowledge for teaching what makes it special? Journal of Teacher Education, 59(5), 389-407. https://doi.org/10.1177/0022487108324554

Borko, H., Jacobs, J., \& Koellner, K. (2010). Contemporary approaches to teacher professional development. In P. Peterson, E. Baker, and B. McGaw (Eds.), International encyclopedia of education (pp. 548- 556). Elsevier. https://doi.org/10.1016/B978-0-08-044894-7.00654$\underline{0}$

Brodie, K. (2014). Learning about learner errors in professional learning communities. Educational Studies in Mathematics, 85, 221-239. https://doi.org/10.1007/s10649-013-9507-1

Clarke, D., \& Hollingsworth, H. (2002). Elaborating a model of teacher professional growth. Teaching and Teacher Education, 18(8), 947-967. https://doi.org/10.1016/S0742-051X(02)00053$\underline{7}$

Council for the Accreditation of Educator Preparation (2015). Standard 2: Clinical partnerships and practice. http://caepnet.org/standards/standard-2

Dudley, P. (2012). Lesson Study development in England: From school networks to national policy. International Journal for Lesson and Learning Studies, 1(1), 85-100. https://doi.org/10.1108/20468251211179722

Fernandez, C. (2002). Learning from Japanese approaches to professional development: The case of lesson study. Journal of Teacher Education, 53(5), 393-405. https://doi.org/10.1177/002248702237394

Fernandez, C. (2005). Lesson study: A means for elementary teachers to develop the knowledge of mathematics needed for reform-minded teaching? Mathematical Thinking and Learning, $7(4)$, 265-289. https://doi.org/10.1207/s15327833mtl0704 1

Fernandez, C., \& Yoshida, M. (2004). Lesson study: A Japanese approach to improving mathematics teaching and learning. Lawrence Erlbaum.

Furner, J., \& Worrell, N. (2017). The importance of using manipulatives in teaching math today. Transformations, 3(1), Article 2. https://nsuworks.nova.edu/transformations/vol3/iss1/2

Kamina, P., \& Tinto, P. (2011). Lesson study: A case of the investigations mathematics curriculum with practicing teachers at fifth grade. In L. Hard, A. Alston, and A. Murata (Eds.), Lesson study research and practice in mathematics education (pp. 221-233). Springer, Dordrecht. https://doi.org/10.1007/978-90-481-9941-9 17

Kilpatrick, J., Swafford J., and Findell B. (Eds.). (2001). Adding it up: Helping children learn mathematics. National Academy Press.

Lewis, C. (2002). Does lesson study have a future in the United States? Nagoya Journal of Education and Human Development, 3(1), 1-24. https://doi.org/10.4119/UNIBI/jsse-v3-i1-967

Lewis, C., \& Hurd, J. (2002). Lesson study step by step: How teacher learning communities improve instruction. Heinemann

Lewis, C., Perry, R., \& Murata, A. (2006). How should research contribute to instructional improvement? The case of lesson study. Educational Researcher, 35(3), 3-14. https://doi.org/10.3102/0013189X035003003

Lewis, C., \& Tsuchida, I. (1999). A lesson is like a swiftly flowing river: How Research Lessons Improve Japanese Education. Improving Schools 2(1):48-56. https://doi.org/10.1177/136548029900200117 
Lewis, J., Fischman, D., Riggs, I., \& Wasserman, K. (2013). Teacher learning in lesson study. The Mathematics Enthusiast, 10(3), 583-620. https://scholarworks.umt.edu/tme/vol10/iss3/5

Murata, A. (2011). Introduction: Conceptual overview of lesson study. In L. Hart, A. Alston, and A. Murata (Eds.), Lesson study research and practice in mathematics education (pp. 1-12). Springer, Dordrecht. https://doi.org/10.1007/978-90-481-9941-9 1

Murata, A., Bofferding, L., Pothen, B., Taylor, M., \& Wischnia, S. (2012). Making connections among student learning, content, and teaching: Teacher talk paths in elementary mathematics lesson study. Journal for Research in Mathematics Education, 43(5), 616-650. https://doi.org/10.5951/jresematheduc.43.5.0616

Pang, J. (2016). Improving mathematics instruction and supporting teacher learning in Korea through lesson study using five practices. ZDMMathematics Education, 48, 471-483. https://doi.org/10.1007/s11858-016-0768-x

Stigler, J., \& Hiebert, J. (1999). The teaching gap: Best ideas from the world's teachers for improving education in the classroom. The Free Press.

Stigler, J., \& Hiebert, J. (2016). Lesson study, improvement, and the importing of cultural routines. ZDMMathematics Education, 48, 581-587. https://doi.org/10.1007/s11858-016-0787-7

Takahashi, A., \& McDougal, T. (2016). Collaborative lesson research: Maximizing the impact of lesson study. ZDMMathematics Education, 48, 513-526. https://doi.org/10.1007/s11858-015$\underline{0752-x}$

Takahashi, A., \& Yoshida, M. (2004). Ideas for establishing lesson-study communities. Teaching Children Mathematics, 10(9), 436-443. https://pubs.nctm.org/view/journals/tcm/10/9/article-p436.xml

Van de Walle, J., Karp, K., Lovin, L., \& Bay-Williams, J. (2018). Teaching student-centered mathematics: Developmentally appropriate instruction for grades 3-5(3rd ed., Vol. 2). Pearson.

Will, M. (2018, August 9). Enrollment Is down at teacher colleges. So they're trying to change. Education Week. https://www.edweek.org/ew/articles/2018/08/09/enrollment-is-down-at-teachercollegesso.html

Yoshida, M. (2012). Mathematics lesson study in the United States: Current status and ideas for conducting high quality and effective lesson study. International Journal for Lesson and Learning Studies, 1(2), 140-152. https://doi.org/10.1108/20468251211224181 